\title{
Der ärztlichen Freiberuflichkeit droht ein Lahnstein 2.0
}

\author{
Gesundheitspolitisch Interessierten ist bekannt, dass mit dem "Kompromiss von Lahnstein" 1992 \\ die Budgetierung in der ambulanten ärztlichen Versorgung in Deutschland eingeführt wurde. \\ Darunter leiden niedergelassene Ärzte bis heute, und infolgedessen haben sich die ambulanten \\ ärztlichen Behandlungsmöglichkeiten in der gesetzlichen Krankenversicherung (GKV) in \\ Deutschland sukzessive verschlechtert. Rationierung, monetäre Fremdbestimmung und zuneh- \\ mender Ärztemangel sind direkte oder indirekte Folgen.
}

\begin{abstract}
Ähnlich gravierendes Ungemach droht nun bei der Novellierung der Gebührenordnung der Ärzte (GOÄ). Nachdem es die Bundesärztekammer (BÄK) seit 1996 nicht geschafft hat, eine Verbesserung der GOÄ zu erreichen, teilte der amtierende BÄKPräsident Montgomery noch zuletzt mit, Streiks und Proteste zur Durchsetzung einer vernünftigen Novellierung kämen für ihn nicht infrage. Wobei, wir erinnern uns, er als Vorsitzender der Ärztegewerkschaft Marburger Bund durchaus weiß und wusste, wie man Arbeitskämpfe organisiert und politischen Druck aufbaut. In dem Kontext war es dann nicht sonderlich überraschend, dass sich die BÄK noch unter dem vorherigen Gesundheitsminister Daniel Bahr auf den Irrweg einließ, unter Auferlegung eines ministeriellen Schweigegelübdes eine gemeinsame Konsentierung ausgerechnet mit dem Verband der Privaten Krankenversicherungen (PKV) zu einer GOÄ-Reform zu finden, die erst dann dem Ministerium vorzulegen sei.
\end{abstract}

\section{Vereinbarung scharf kritisiert}

Im Herbst 2013 wurde daraufhin eine Vereinbarung zwischen BÄK und PKV-Verband präsentiert, die seitens der Freien Ärzteschaft bereits damals scharf kritisiert wurde. Breite innerärztliche Kritik kam jedoch erst nach dem Entwurf zur Änderung der Bundesärzteordnung im Herbst 2015 auf, der die Schaffung einer "Gemeinsamen Kommission“ aus Ärzten, PKV und Vertretern der Länder beinhaltet. Diese Kommission soll erhebliche Regelungsbefugnisse haben: neue Leistungen definieren, die abgerechnet werden dürfen, einen Katalog für oder gegen die Steigerungsmöglichkeit von GOÄ-Ziffern festlegen, Kriterien für ärztliche Qualifikation, Qualität der Leistungserbringung, Formales zur Rechnungslegung und vieles mehr bestimmen. Dieses basierend auf den Daten einer neu zu schaffenden Datenstelle, die ärztliche Abrechnungsdaten penibel sammelt. Wenn am Ende auch das Bundesgesundheitsministerium der Verordnungsgeber bleibt, so kommt der Kommission doch erhebliche Bedeutung zu. Ihre Aufgabenstellung ähnelt der des Gemeinsamen Bundesausschusses und des Bewertungsausschusses in der GKV, sodass zahlreiche Kritiker die GOÄ auf dem Weg weg von einer Gebührenord- nung des freien Berufs Arzt, hin zu einer Versozialrechtlichung sehen. Die Kommission soll Aufgaben der globalen Kostenmessung, -kontrolle und -korrektur bekommen. Und: Die GOÄ soll grundsätzlich nur noch den Einfachsatz einer Gebühr beinhalten, worin viele den Weg in die Einheitsmedizin sehen - mit patientenindividueller Abrechnung im Rahmen freier ärztlicher Berufsausübung hat das jedenfalls nichts zu tun.

\section{Möglicherweise ein Interessenkonflikt}

Nach zunehmender Kritik, an der sich auch die Bundeszahnärztekammer beteiligte, fand der außerordentliche Ärztetag in Berlin statt, dessen Ergebnis die BÄK als Bestätigung ihres Vorgehens in Sachen GOÄ sieht. Die Freie Ärzteschaft ist da ganz anderer Auffassung, und es gibt zahlreiche Kritiker, die diese Bewertung ebenfalls ablehnen. Die Verhandlungsführung des Präsidenten Montgomery war von Einseitigkeit und Verfahrenstricks geprägt - er als selbst Betroffener hätte die Tagungsleitung korrekt abgeben müssen. Änderungsanträge zum vorliegenden Entwurf wurden pauschal und unangemessen abgebügelt.

Zudem macht der Tatbestand nachdenklich, dass gleich mehrere Mitglieder des BÄK-Vorstands (inklusive des Präsidenten selber) dotierte Mitglieder im sogenannten Ärztebeirat der Allianz (Nummer vier in der Liste der größten privaten deutschen Krankenversicherer) sind. Vorsitzende dieses Gremiums ist eben jene Frau König, die für die PKV-Seite die Verhandlungen zur GOÄ führt. Da stellt sich möglicherweise die Frage nach einem Interessenkonflikt.

Die innerärztliche Diskussion um die Zukunft der GOÄ ist in vollem Gang - der Sonderärztetag konnte so keinesfalls zu einer Befriedung führen. Es wäre hilfreich, wenn sich auch die mitbetroffene Zahnärzteschaft weiter kritisch in die Debatte um eine neue Gebührenordnung für Ärzte einbringt!

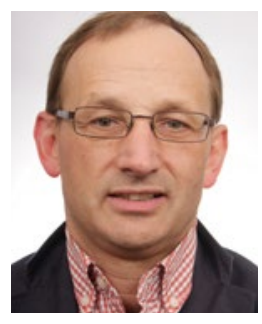

Wieland Dietrich

Vorsitzender der Freien Ärzteschaft 